\title{
Incarceration And Its \\ Disseminations: COVID-19 \\ Pandemic Lessons From Chicago's Cook County Jail
}

Eric Reinhart (reinhar@fas harvard.edu) is a PhD candidate in the Department of Anthropology, Harvard University, in Cambridge, Massachusetts, and an MD candidate at the University of Chicago Pritzker School of Medicine, in Chicago, Illinois. $\mathrm{He}$ is also a candidate in adult psychoanalysis at the Chicago Center for Psychoanalysis.

Daniel L. Chen is a director of research at the Centre National de la Recherche Scientifique (CNRS), in Paris, France; a professor at the Toulouse School of Economics and Université de Toulouse Faculty of Law, in Toulouse, France; and lead principal investigator of the DE JURE (Data and Evidence for Justice Reform) Program at the World Bank in Washington, D.C.
ABSTRACT Jails and prisons are major sites of novel coronavirus (SARSCoV-2) infection. Many jurisdictions in the United States have therefore accelerated the release of low-risk offenders. Early release, however, does not address how arrest and pretrial detention practices may be contributing to disease spread. Using data from Cook County Jail-one of the largest known nodes of SARS-CoV-2 spread in the United States-in Chicago, Illinois, we analyzed the relationship between jailing practices and community infections at the ZIP code level. We found that jailcommunity cycling was a significant predictor of cases of coronavirus disease 2019 (COVID-19), accounting for 55 percent of the variance in case rates across ZIP codes in Chicago and 37 percent of the variance in all of Illinois. Jail-community cycling far exceeds race, poverty, public transit use, and population density as a predictor of variance. The data suggest that cycling people through Cook County Jail alone is associated with 15.7 percent of all documented COVID-19 cases in Illinois and 15.9 percent of all documented cases in Chicago as of April 19, 2020. Our findings support arguments for reduced reliance on incarceration and for related justice reforms both as emergency measures during the present pandemic and as sustained structural changes vital for future pandemic preparedness and public health.

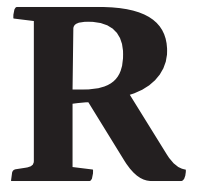

elative to peer nations, the United States relies disproportionately on arrest and incarceration in its criminal justice administration. In 2018 there were more than ten million arrests, five million arrestees cycled through jails, and two million incarcerated people in the United States, accounting for nearly a quarter of the total incarcerated population worldwide. ${ }^{1-3}$ As a result, many of the country's jails and penitentiaries are severely overcrowded. ${ }^{4}$ The coronavirus disease 2019 (COVID-19) pandemic presents an urgent public health incentive for reconsidering the logic of punishment and reducing reliance on arrest and incarceration. ${ }^{5-9}$ Such a shift would coincide with important political and ethical arguments for reforming policing and carceral policy. ${ }^{10-12}$

Existing conditions in jails and penitentiaries make infection control particularly difficult, putting inmates at unconscionable and perhaps unconstitutional risk. ${ }^{13}$ The outbreak at Cook County Jail, in Chicago, Illinois, which was the largest known node of SARS-CoV-2 spread in the country until it was surpassed by a state prison in Ohio, makes this reality plain. ${ }^{14-16}$ In light of the risk of epidemics in densely populated carceral facilities, many jurisdictions have begun releasing certain low-risk offenders from jails and prisons to mitigate the risks posed to inmates with conditions that render them more vulnerable to severe COVID-19. ${ }^{17}$ While the ratio- 
nale for the continued confinement of some people is being reevaluated under pandemic conditions, public health concerns suggest that it is also important to reconsider the public safety justification for initial arrest and incarceration policies. ${ }^{6-9}$ Relevant context for such reconsideration includes estimates that for 39 percent of incarcerated people in the prison system, which houses those already convicted of crimes, there is no public safety justification for their confinement. ${ }^{18,19}$ In pretrial detention facilities (that is, jails) in two counties similar to Cook County, approximately 42 percent of pretrial detainees are not found guilty of criminal allegations. ${ }^{20}$ Furthermore, 95 percent of jail detainees nationally are held for nonviolent alleged offenses. ${ }^{21}$ In this context, the proportion of people jailed without a public safety justification for their detention is very high.

Early policy discussions around the infection risk posed by incarceration during the COVID-19 pandemic focused on prison epidemics and the need for associated changes in release policy, such as commutations and compassionate release. ${ }^{22}$ These release-oriented approaches, which are necessary for the ethical treatment of incarcerated people during a pandemic, are not adequate to address the ways in which ongoing arrest and pretrial detention practices in jails may be contributing to disease spread in community contexts. This broader discussion goes beyond prison epidemics to consider the consequences of policing practices and jailcommunity cycling for SARS-CoV-2 spread. It has more recently begun to attract appropriate attention, including in a non-peer-reviewed modeling study produced by the American Civil Liberties Union in collaboration with several universities, which is based on extensive simulations but little evidence. ${ }^{23}$

Our research evaluates how the infection risk to people processed through the jail system may multiply into a generalized risk to the public after people's arrest and subsequent cycling into and out of jails as they await hearings and trials. The data analysis of empirical evidence in our study offers a supplement to modeling studies, which, in the absence of strong available evidence, necessarily rely on various assumptions about SARS-CoV-2 infectivity in jails and prisons, spread in community contexts after inmate release, rates of symptomatic expression and detection among infected people, mortality rates, and other estimated variables to simulate various scenarios. ${ }^{24}$ Our analysis of jail-community cycling and community spread of SARS-CoV-2 presents preliminary evidence concerning Cook County Jail and the state of Illinois that should be followed by larger studies that can further strengthen the evidentiary basis for modeling and managing an ongoing public health crisis.

\section{Study Data And Methods}

DATA SOURCES The scale of jail-community cycling and its potential for infection seeding is significant. For example, in March 2020, 1,855 people were booked into Cook County Jail in Chicago, and 2,129 were released to Illinois ZIP codes; 92 percent of the latter group had been booked into the jail after February 1, 2020. We examined this epidemiological connection between jail and community at the ZIP code level, using booking, release, and COVID-19 data obtained from Cook County Jail, demographic data from the 2010 US census and the 2011 American Community Survey (the most recent years for which ZIP code-level data are available), and COVID-19 data reported by the Illinois Department of Public Health.

ANALYSIS To evaluate the relative strength of the correlation between Cook County Jail-community cycling and COVID-19 spread in the city of Chicago and the state of Illinois, we ran bivariate and multivariate regressions between the COVID-19 case rate and five variables by ZIP code: jail inmates released in March 2020, proportion of black residents, poverty rate, public transit utilization rate, and population density.

LIMITATIONS Our analysis necessarily relied on the assumption that arrests and releases are unrelated to omitted factors that may be associated with COVID-19 across ZIP codes. We therefore could not rule out in this descriptive study the possibility of reverse causality, which might suggest that high rates of COVID-19 in communities subject to higher jailing rates preceded spread from the jail and thus confound a causal flow of COVID-19 from jails to communities. However, other causal factors determining COVID-19 case rates are plausibly associated with the other demographic controls we used, which we found did not account for the correlation we observed between jail-community cycling and COVID-19.

Furthermore, it is important to note that the mechanism of reverse causality would not have a straightforward operation in relation to the spread of COVID-19 as a result of jail-community cycling, since community-acquired cases introduced into a jail setting could multiply during jail intake and release procedures and then spread back to the community in greater numbers. Although a randomized controlled trial remains the only thoroughly rigorous method by which to rule out reverse causality, ${ }^{25}$ we are currently examining the issue of reverse causality in greater depth with new longitudinal data that allow further examination of any such remaining 
concerns.

Another methodological limitation follows from the lack of available data that would have allowed us to incorporate spatial network analyses to account for possible issues of adjacency and spillover between ZIP codes. Concerns about this limitation, however, should be mitigated by the fact that incorporation of spatial network spillover effects would likely produce true effects larger than the estimates given in our results here. This is because spillovers in our study context-where "control" ZIP codes are contaminated by "treatment" ZIP codes-would dampen the contrasts between ZIP codes with high and low release numbers. To have used such spatial network analysis in an appropriately rigorous manner, we would have needed a randomized controlled trial of peer ZIP codes to estimate peer spillover across ZIP codes (for example, randomization of whether transportation networks facilitate connections between one peer ZIP code and another). ${ }^{26}$ Such data, which remain unavailable to us, would then allow for measurements using geographic information systems (GIS).

In terms of generalizability, we used data only from Illinois and a single county jail: Cook County Jail, the largest single-site jail and third-largest jail system in the US. Cook County is the second most populous US county, which makes its activities relevant even if they are not representative of smaller counties. The association between Cook County Jail and COVID-19 that we documented both in Chicago and statewide in Illinois does not appear driven by outliers, which alleviates possible concerns that sampling factors drove the correlations we report. As we note below, these correlations persisted in our analysis of the raw data and in multiple regressions that include controls.
The presence of minimal data concerning jail staff is another limitation. According to data we obtained from the Cook County Sheriff's Office, there were more than six hundred infections within the jail as of April 19; more than a hundred of these were among jail staff. These infections among staff are accounted for within institutional reporting but were not included in our community-level COVID-19 data. However, one might expect that staff members who enter and leave the jail daily would have unusually high potential for seeding SARS-CoV-2 in their communities. Unfortunately, we did not have ZIP code-level data on the place of residence of jail staff that would enable us to account for their potential role in community spread. If we had been able to account for staff-associated community spread of SARS-CoV-2 in our analysis, we expect that the association between Cook County Jail and community infection rates would be even greater than we have been able to demonstrate with the available data.

\section{Study Results}

Exhibit 1 provides details on the variables mentioned earlier (jail inmates released in March, poverty rate, public transit utilization rate, proportion of black residents, and population density) for ZIP codes both in Chicago and statewide in Illinois (limiting to ZIP codes with at least five cases of COVID-19 as of April 19), along with summary statistics. It shows that, in comparison with the rest of Illinois, Chicago ZIP codes are poorer, have greater use of public transit, and have a higher proportion of black residents and higher population density.

Bivariate correlations between COVID-19 case rates and these five variables are presented in

EXHIBIT 1

Estimated relationships among COVID-19 cases per capita in Chicago and the state of Illinois as of April 19, 2020, with number of Cook County Jail inmates released in March 2020 and other variables from bivariate regression analysis

\begin{tabular}{|c|c|c|c|c|}
\hline \multirow[b]{2}{*}{ Characteristics } & \multicolumn{2}{|c|}{ Chicago ( $n=50)$} & \multicolumn{2}{|c|}{ Illinois ( $n=355$ ) } \\
\hline & Mean & SD & Mean & SD \\
\hline COVID-19 cases per capita & 0.005 & 0.002 & 0.003 & 0.002 \\
\hline Poverty rate & 0.242 & 0.159 & 0.117 & 0.116 \\
\hline Public transit utilization rate & 0.251 & 0.098 & 0.079 & 0.090 \\
\hline Population density & 15,433 & 8,016 & 4,276 & 5,895 \\
\hline Population $^{a}$ & 52,545 & 24,304 & 27,815 & 18,818 \\
\hline
\end{tabular}

source Authors' analysis of data from Cook County Jail, Illinois Department of Public Health, 2010 US census, and 2011 American Community Survey. Notes Sample sizes are numbers of ZIP codes in Chicago and in Illinois. Sample is restricted to ZIP codes with five or more COVID-19 cases as of April 19, 2020 (the minimum requirement set by the Illinois Department of Public Health for reporting by ZIP code). SD is standard deviation. ${ }^{\text {Mean }}$ population per ZIP code. 
Estimated relationships among COVID-19 cases per capita in Chicago and the state of Illinois, number of Cook County Jail inmates released in March 2020, and other variables from bivariate regression analysis, April 2020

Independent variables
SAMPLE: CHICAGo
Inmates released in March 2020 per cap
Poverty rate
Public transit utilization rate
Proportion of black residents
Population density
sAmpLE: ILLINoIs
Inmates released in March per capita
Poverty rate
Public transit utilization rate
Proportion of black residents
Population density

Population density

$\begin{array}{lll}\text { Parameter estimates } & \mathbf{p} \text { value } & \boldsymbol{R}^{\mathbf{2}} \\ & & \\ 2.207 & <0.001 & 0.551 \\ 0.00551 & <0.001 & 0.261 \\ 0.00139 & >0.10 & 0.006 \\ 0.00307 & <0.001 & 0.406 \\ 0.0000000403 & >0.10 & 0.035 \\ & & \\ 4.065 & <0.001 & 0.367 \\ 0.00518 & <0.001 & 0.094 \\ 0.0110 & <0.001 & 0.256 \\ 0.00442 & <0.001 & 0.301 \\ 0.000000152 & <0.001 & 0.209\end{array}$

source Authors' analysis of data from Cook County Jail, Illinois Department of Public Health, 2010 US census, and 2011 American Community Survey. Nore Sample is restricted to ZIP codes with five or more COVID-19 cases as of April 19, 2020 (the minimum requirement set by the Illinois Department of Public Health for reporting by ZIP code).

exhibit 2. This exhibit shows that in the city of Chicago, released jail inmates, poverty, and proportion of black residents were significantly positively correlated with COVID-19 case rate, with $R^{2}$ values of $0.55,0.26$, and 0.41 , respectively. The parameter estimate of 2.2 for inmates released in March 2020 per capita, for instance, indicates that one released jail inmate per capita corresponds to 2.2 additional cases per capita. Statewide in Illinois, all variables were significantly positively correlated with COVID-19, with $R^{2}$ values of 0.37 (released jail inmates), 0.09 (poverty), 0.26 (public transit utilization), 0.30 (proportion of black residents), and 0.21 (population density).

In multivariate linear regression restricted to Chicago, the significant positive associations with race and poverty disappear, whereas the association with released inmates remains significant at the 0.10 percent level (exhibit 3 ). The coefficient estimate of 1.8 for inmates released in March 2020 per capita, for example, indicates that one released jail inmate per capita corresponds to 1.8 additional cases per capita after the other variables mentioned above are controlled for. A negative coefficient would indicate that a variable is associated with fewer cases per capita after the other variables are controlled for. Exhibit 4 presents a scatter plot of this relationship; online appendix exhibit 1 presents scatter plots of all the other relationships. ${ }^{27}$ In multivariate regression for Illinois, positive associations with released inmates, race, and population density remain significant at the 0.10 percent level. Exhibit 3 presents the regression coefficients. Rendered in absolute population terms (as in the lower half of exhibit 3), multivariate regres- sions suggest that the cycling of 2,129 people through Cook County Jail in March was associated with 4,575 additional known community infections in Illinois as of April 19. We arrived at this last number by multiplying the number of released inmates by the regression coefficient (2.149). In Chicago ZIP codes, the number of released inmates $(1,252)$ multiplied by the regression coefficient (1.548) suggests that 1,938

\section{EXHIBIT 3}

Estimated relationships among COVID-19 cases per capita in Chicago and the state of Illinois, number of Cook County Jail inmates released, and other variables from multivariate regression analysis, April 2020

Regression coefficients

\begin{tabular}{|c|c|c|}
\hline \multirow[b]{2}{*}{ Independent variables } & \\
\hline & Chicago & Illinois \\
\hline \multicolumn{3}{|c|}{ COEFFICIENTS FOR COVID-19 CASES PER CAPITA } \\
\hline $\begin{array}{l}\text { Inmates released in March } 2020 \text { per capita } \\
\text { Poverty rate } \\
\text { Public transit utilization rate } \\
\text { Proportion of black residents } \\
\text { Population density } \\
R^{2}\end{array}$ & $\begin{array}{l}1.874 \text { wherk } \\
0.000153 \\
-0.00527 \\
0.00131 \\
0.000000027 \\
0.601\end{array}$ & 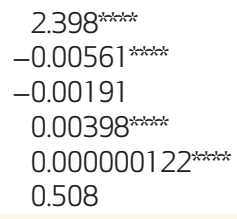 \\
\hline \multicolumn{3}{|c|}{ COEFFICIENTS FOR COVID-19 CASES IN ABSOLUTE POPULATION } \\
\hline $\begin{array}{l}\text { Inmates released in March } \\
\text { Population living in poverty } \\
\text { Population using public transit } \\
\text { Proportion of black residents } \\
\text { Population density } \\
\text { Population } \\
R^{2}\end{array}$ & 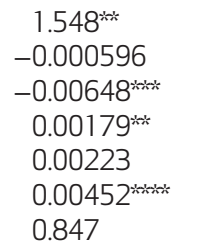 & 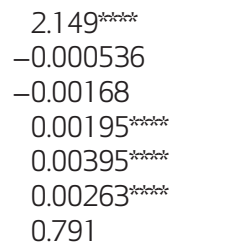 \\
\hline
\end{tabular}

SOURCE Authors' analysis of data from Cook County Jail, Illinois Department of Public Health, 2010 US census, and 2011 American Community Survey. Note Sample is restricted to ZIP codes with five or more COVID-19 cases as of April 19, 2020 (the minimum requirement set by the Illinois

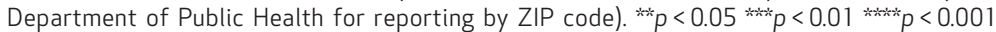


additional Chicago cases were associated with the jail.

These numbers would represent 15.7 percent of all documented COVID-19 cases in Illinois and 15.9 percent in Chicago as of April 19. We calculated these percentages by dividing 1,938 (additional cases in Chicago) by the total number of COVID-19 cases in Chicago at that date (as reported by the Illinois Department of Public Health) and, likewise, dividing 4,575 (additional cases in Illinois) by the total number for Illinois. Our data thus suggest that a much higher number of cases is linked to the jail than limited contact tracing has established. ${ }^{7}$ Our results are robust to the inclusion of all Illinois ZIP codes with fewer than five reported COVID-19 community infections (the limited number required by Illinois Department of Public Health for them to report cases by ZIP code) by assigning them a value of zero infections. See appendix exhibit 2 for this analysis and appendix exhibits 3 and 4 for additional models and specifications. ${ }^{27}$

\section{Discussion}

This analysis has shown that as of April 19, 2020, COVID-19 case rates in Chicago were significantly higher in ZIP codes with higher rates of arrests and released jail inmates from the Cook County Jail. We found that jail-community cycling was a significant predictor of SARS-CoV-2 infection, accounting for 55 percent of the variance in case rates across ZIP codes in Chicago and 37 percent in Illinois. Jail-community cycling far exceeds race, poverty, public transit use, and population density as a predictor of variance.

Although currently available data are inadequate to establish a clear causal relation, these provisional findings are consistent with the hypothesis that arrest and jailing practices are augmenting infection rates in highly policed neighborhoods. Although we cannot infer causality, it is possible that because arrested people are exposed to high-risk spaces for infection in jails and then later released to their communities, the criminal justice system is turning them into po-

EXHIBIT 4

Scatter plot analysis of COVID-19 cases in Chicago, Illinois, March 2020

$0.010-$

0.009

0.008

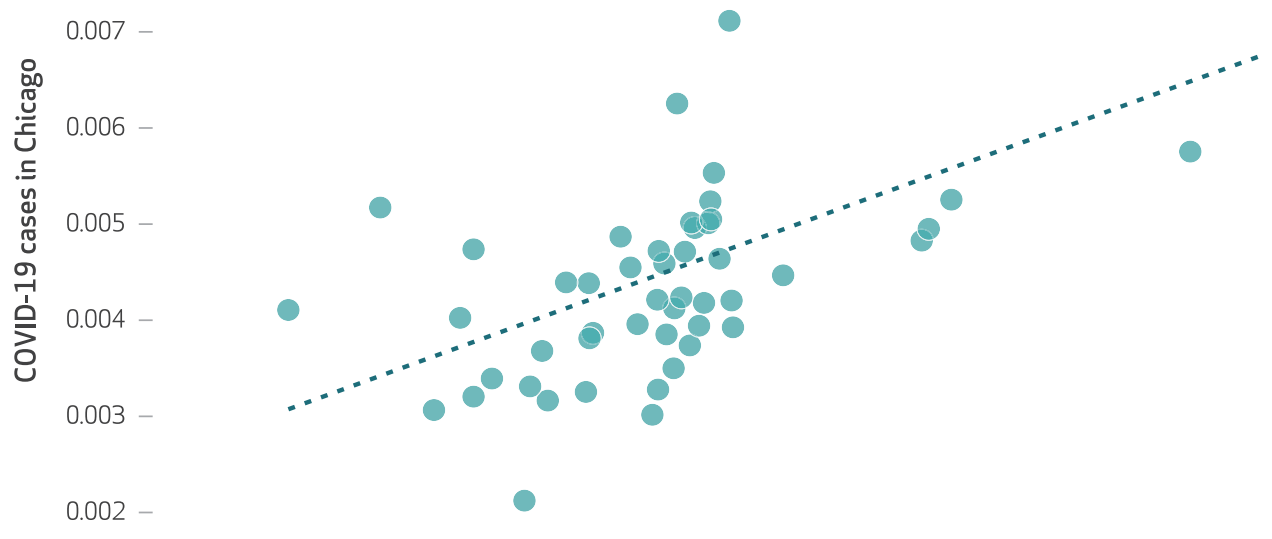

0.001

0.000

0.0000

$\begin{array}{ccc}0.0005 & 0.0010 & 0.0015 \\ \text { Inmates released from the Cook County Jail } & \end{array}$

SOURCE Authors' analysis of data from Cook County Jail, Illinois Department of Public Health, 2010 US census, and 2011 American Community Survey. Noтrs This scatter plot represents a relationship between COVID-19 cases per capita and inmates released in March 2020 per capita in Chicago, Illinois, after residualizing on poverty rate, public transit utilization rate, proportion of black residents, and population density. Sample is restricted to ZIP codes with five or more COVID-19 cases as of April 19, 2020 (the reporting requirement by the Illinois Department of Public Health for reporting by ZIP code). 
The criminal justice system is one among many social structures being subjected to renewed scrutiny during the COVID-19 pandemic.

tential disease vectors for their families, neighbors, and ultimately the general public. In light of the well-documented, disproportionate intensity of policing and incarceration in black neighborhoods in the United States, the carceralcommunity spread of disease may bear partial responsibility for the striking racial disparities noted in COVID-19 cases. ${ }^{12}$ In Chicago, although black residents make up only 30 percent of the population, they represent 75 percent of the Cook County Jail population and 72 percent of the city's COVID-19-related deaths. ${ }^{28,29}$

Our findings reinforce arguments that efforts to shift criminal justice administration away from arrest and incarceration may be vital for protecting the public health during this pandemic and reducing vulnerability to future epidemics. ${ }^{5-9,19}$ Waiting to implement changes in the criminal justice system until epidemic outbreaks become apparent, as in the present case, is not sufficient and will not protect against a reprise of the current situation. The COVID-19 pandemic is making clear that alternative mechanisms of criminal deterrence such as citations, public service requirements, and supervised release are not only more humane policies in accordance with international standards of human rights but also sound public health policy in a globalized era of vulnerability to the rapid spread of infectious diseases. ${ }^{2,4-12,30}$

We hope that the findings and conclusions presented here will be followed by further studies with more comprehensive data, including longitudinal COVID-19 data, that were unavailable for this first empirical study of the relationship between incarceration and community spread of COVID-19. Important related areas for further research include analyses of the effects of arrest policies on COVID-19 spread in communities; the effects of infection control measures taken within jails and prisons on the risk of community spread; COVID-19 cases associated with the daily circulation of jail and prison staff between carceral facilities and their home communities; and the association between early release policies and COVID-19 cases and mortality among incarcerated populations.

\section{Conclusion}

The criminal justice system in the United States is just one among many existing social structures that are being subjected to renewed scrutiny during the COVID-19 pandemic because of the public health hazards they pose. Pandemic reality has brought humanity to an unprecedented collective realization of national and global interconnectedness in which the risks of vulnerability to disease for America's incarcerated and the world's poor, for example, threaten everyone, although clearly not equally. ${ }^{31-34}$
Daniel L. Chen acknowledges support from the Centre National de la Recherche Scientifique (CNRS), in Paris, France, for his position as a CNRS director of research, as well as from a research grant from the Knowledge for Change Program. The findings, interpretations, and conclusions expressed do not necessarily reflect the views of the funders or employers. An unedited version of this article was published online June 4, 2020, as a Fast Track Ahead Of Print article. That version is available in the online appendix.

\section{NOTES}

1 Wagner P, Sawyer W. States of incarceration: the global context 2018 [Internet]. Northampton (MA): Prison Policy Initiative; 2018 Jun [cited 2020 Jun 11]. Available from: https://www.prisonpolicy.org/ global/2018.html

2 Heard C. Towards a health-informed approach to penal reform? Evidence from ten countries [Internet]. London: Birkbeck, University of London, Institute for Criminal Policy
Research; 2019 Jun [cited 2020 Jun 11]. Available from: https://www .prisonstudies.org/sites/default/ files/resources/downloads/icpr_ prison_health_report.pdf

3 Federal Bureau of Investigation. Crime in the U.S. 2018 [Internet]. Washington (DC): FBI; [cited 2020 Jun 11]. Available from: https:// ucr.fbi.gov/crime-in-the-u.s/2018/ crime-in-the-u.s.-2018

4 American Civil Liberties Union.
Overcrowding and overuse of imprisonment in the United States. American Civil Liberties Union (ACLU) Submission to the Office of the High Commissioner for Human Rights [Internet]. New York (NY): ACLU; 2015 May [cited 2020 Jun 11]. Available from: https://www.ohchr .org/Documents/Issues/RuleOf Law/OverIncarceration/ACLU.pdf

5 Wurcel AG, Dauria E, Zaller N, Nijhawan A, Beckwith C, Nowotny K, 
et al. Spotlight on jails: COVID-19 mitigation policies needed now. Clin Infect Dis. 2020 Mar 28 [Epub ahead of print].

6 Hawks L, Woolhandler S, McCormick D. COVID-19 in prisons and jails in the United States. JAMA Intern Med. 2020 Apr 28 [Epub ahead of print].

7 Akiyama MJ, Spaulding AC, Rich JD. Flattening the curve for incarcerated populations-COVID-19 in jails and prisons. N Engl J Med. 2020; 382(22):2075-7.

8 Nowotny K, Bailey Z, Omori M, Brinkley-Rubinstein L. COVID-19 exposes need for progressive criminal justice reform. Am J Public Health. 2020;110(7):967-8.

9 Barnert E, Ahalt C, Williams B. Prisons: amplifiers of the COVID-19 pandemic hiding in plain sight. Am J Public Health. 2020;110(7):964-6.

10 Roberts DE. The Supreme Court 2018 term: foreword: abolition constitutionalism. Harvard Law Review [serial on the Internet]. 2019 Nov [cited 2020 Jun 11]. Available from: https://harvardlawreview.org/wpcontent/uploads/2019/11/1-122 Online.pdf

11 Gilmore RW. Golden gulag: prisons, surplus, crisis, and opposition in globalizing California. Berkeley (CA): University of California Press; 2007.

12 On mass incarceration [special issue]. Daedalus. 2010 Summer; 139(3).

13 Wallace M, Hagan L, Curran KG, Williams SP, Handanagic S, Bjork A, et al. COVID-19 in correctional and detention facilities-United States, February-April 2020. MMWR Morb Mortal Wkly Rep. 2020;69(19): 587-90.

14 Cook County Sheriff [Internet]. Chicago (IL): Cook County Sheriff; 2020. Press release, COVID-19 cases at CCDOC; 2020 Jun 10 [cited 2020 Jun 11]. Available from: https:// www.cookcountysheriff.org/covid19-cases-at-ccdoc/

15 Ohio Department of Rehabilitation and Correction. COVID-19 inmate testing [Internet]. Columbus $(\mathrm{OH})$ : DRC; [last updated 2020 Apr 20; cited 2020 Jun 11]. Available from: https://www.drc.ohio.gov/Portals/ 0/DRC\%20COVID-19\%20 Information\%2004-20-2020\%20 \%201304_1.pdf

16 Rojas R, Cooper M. Georgia, Tennessee, and South Carolina say businesses can reopen soon. New York Times [serial on the Internet]. 2020 Apr 20 [cited 2020 Jun 11]. Available from: https://www .nytimes.com/2020/04/20/us/ coronavirus-us-hot-spotsreopening.html

17 Williams T, Weiser B, Rashbaum WK. "Jails are petri dishes": inmates freed as the virus spreads behind bars. New York Times [serial on the Internet]. 2020 Mar 30 [last updated 2020 May 20; cited 2020 Jun 11]. Available from: https://www .nytimes.com/2020/03/30/us/ coronavirus-prisons-jails.html

18 Austin J, Eisen L-B, Cullen J, Frank J. How many Americans are unnecessarily incarcerated? [Internet]. New York (NY): NYU School of Law, Brennan Center for Justice; 2016 [cited 2020 Jun 12]. Available from: https://www.brennancenter.org/ sites/default/files/2019-08/ Report_Unnecessarily_ Incarcerated_0.pdf

19 Margulies J. Let the people go. Boston Review [serial on the Internet]. 2020 Apr 20 [cited 2020 Jun 11]. Available from: http://boston review.net/law-justice/josephmargulies-prisons-and-pandemics

20 Dobbie W, Goldin J, Yang CS. The effects of pretrial detention on conviction, future crime, and employment: evidence from randomly assigned judges. Am Econ Rev. 2018;108(2):201-40.

21 Vera Institute of Justice. Arrest trends: how many arrests are made annually, and for what? [Internet]. Brooklyn (NY): The Institute; [last updated 2020 Jun 30; cited $2020 \mathrm{Jul}$ 1]. Available from: https:// arresttrends.vera.org/

22 Editorial Board. No one deserves to die of Covid-19 in jail. New York Times [serial on the Internet]. 2020 Apr 23 [cited 2020 Jun 11]. Available from: https://www.nytimes.com/ 2020/04/23/opinion/coronavirusprisons.html

23 American Civil Liberties Union. COVID-19 model finds nearly 100,000 more deaths than current estimates, due to failures to reduce jails [Internet]. New York (NY): ACLU; 2020 Apr 22 [cited 2020 Jun 11]. Available from: https://www .aclu.org/sites/default/files/field_ document/aclu_covid19-jail-report_ 2020-8_1.pdf

24 Fuller J. Models v. evidence. Boston Review [serial on the Internet]. 2020
May 5 [cited 2020 Jun 11]. Available from: http://bostonreview.net/ science-nature/jonathan-fullermodels-v-evidence

25 Angrist JD, Pischke JS. The credibility revolution in empirical economics: how better research design is taking the con out of econometrics. J Econ Perspect. 2010;24(2): 3-30.

26 Manski CF. Identification of endogenous social effects: the reflection problem. Rev Econ Stud. 1993; 60(3):531-42.

27 To access the appendix, click on the Details tab of the article online.

28 Foody K. Rate of deaths, illness among black residents alarms cities. Associated Press [serial on the Internet]. 2020 Apr 6 [cited 2020 Jun 11]. Available from: https://apnews .com/1862bf401d6aad1d182e0bd $967488 \mathrm{c} 90$

29 Jimenez O. Chicago's biggest jail has released almost a fourth of its population over coronavirus fears. CNN [serial on the Internet]. 2020 Apr 17 [cited 2020 Jun 11]. Available from: https://www.cnn.com/2020/04/17/ us/cook-county-jail-coronavirius/ index.html

30 Kahan DM. What do alternative sanctions mean? Univ Chic Law Rev. 1996;63(2):591-653.

31 Stafford K, Hoyer M, Morrison A. Outcry over racial data grows as virus slams black Americans. Associated Press [serial on the Internet]. 2020 Apr 8 [cited 2020 Jun 11]. Available from: https://apnews .com/71d952faad4a2a5d14441534f $7230 \mathrm{c} 7 \mathrm{c}$

32 Yancy CW. COVID-19 and African Americans. JAMA. 2020;232(19): 1891-2.

33 Gordon C, Johnson W, Purnell JQ, Rogers J. COVID-19 and the color line. Boston Review [serial on the Internet]. 2020 May 1 [cited 2020 Jun 11]. Available from: http:// bostonreview.net/race/colingordon-walter-johnson-jason-qpurnell-jamala-rogers-covid-19-andcolor-line

34 Gross CP, Essien UR, Pasha S, Gross JR, Wang S, Nunez-Smith M. Racial and ethnic disparities in population level Covid-19 mortality. MedRxiv [serial on the Internet]. 2020 May 7 [cited 2020 Jun 11]. Available from: https://www.medrxiv.org/content/ $10.1101 / 2020.05 .07 .20094250 \mathrm{v} 1$ 